\title{
Electrospinning of Cross-Linked Magnetic Chitosan Nanofibers for Protein Release
}

\author{
Ehsan Tayerani Nicknejad, ${ }^{1}$ Seyyed Mohammad Ghoreishi, ${ }^{1,3}$ and Neda Habibi ${ }^{2}$
}

\begin{abstract}
Received 16 February 2015; accepted 15 May 2015; published online 29 May 2015
Abstract. A poly(vinylalcohol) (PVA) electrospun/magnetic/chitosan nanocomposite fibrous cross-linked network was fabricated using in situ cross-linking electrospinning technique and used for bovine serum albumin (BSA) loading and release applications. Sodium tripolyphosphate (TPP) and glutaraldehyde (GA) were used as cross-linkers which modified magnetic- $\mathrm{Fe}_{3} \mathrm{O}_{4}$ chitosan as $\mathrm{Fe}_{3} \mathrm{O}_{4} / \mathrm{CS} / \mathrm{TPP}$ and $\mathrm{Fe}_{3} \mathrm{O}_{4} \mathrm{CS} / \mathrm{GA}$, respectively. BSA was used as a model protein drugs which was encapsulated to form $\mathrm{Fe}_{3} \mathrm{O}_{4} / \mathrm{CS} / \mathrm{TPP} / \mathrm{BSA}$ and $\mathrm{Fe}_{3} \mathrm{O}_{4} / \mathrm{CS} / \mathrm{GA} / \mathrm{BSA}$ nanoparticles. The composites were electrospun with PVA to form nanofibers. Nanofibers were characterized by field emission scanning electron microscopy (FESEM) and Fourier transform infrared spectroscopy (FTIR). The characterization results suggest that $\mathrm{Fe}_{3} \mathrm{O}_{4}$ nanoparticles with average size of $45 \mathrm{~nm}$ were successfully bound on the surface of chitosan. The cross-linked nanofibers were found to contain uniformly dispersed $\mathrm{Fe}_{3} \mathrm{O}_{4}$ nanoparticles. The size and morphology of the nanofibers network was controlled by varying the cross-linker type. FTIR data show that these two polymers have intermolecular interactions. The sample with TPP cross-linker showed an enhancement of the controlled release properties of BSA during 30-h experimental investigation.
\end{abstract}

KEY WORDS: cross-linker; electrospun; magnetite; mano-composite; protein loading.

\section{INTRODUCTION}

Recently, electrospinning technology has emerged as a versatile process of fabricating nanofibers. Different methods are reported to produce biomimetic non-woven materials comprising a large network of interconnected fibers and pores $(1,2)$. A large number of biomacromolecules, such as poly(e-caprolactone), poly(lactic acid), poly(lactide-coglycoside), collagen, and gelatin have been successfully fabricated into non-woven mats by the electrospinning method (3-5). Especially, a series of electrospun nanofibers based on chitin and chitosan have gained a great attention owing to their extensive biomedical applications in such as tissue engineering scaffolds and drug delivery (6). Electrospun nanofibrous membranes are considered to be of great potential in the field of tissue regeneration, since they can closely mimic the extracellular matrix architecture (7-11). The electrospinning process also provides operational flexibility for incorporating multiple components into nanofiber, such as metal nanoparticles and inorganic nanoparticles (12-17). Magnetic nanoparticles (NPs) are of enormous importance for their prospective biomedical applications such as magnetic resonance imaging

\footnotetext{
${ }^{1}$ Chemical Engineering, Isfahan University of Technology, Isfahan, 84156-83111, Iran.

${ }^{2}$ Nanotechnology and Advanced Material Institute, Isfahan University of Technology, Isfahan, Iran.

${ }^{3}$ To whom correspondence should be addressed. (e-mail: ghoreshi@cc.iut.ac.ir)
}

(MRI), tissue repair, immunoassay, detoxification of biological fluids, hyperthermia, and drug delivery. As well, electrospinning technique had been successfully used in fabricating magnetic fibrous scaffolds (18). Wei et al. applied magnetic chitosan electrospun nanofibers for bone regeneration purposes (19). In the field of drug delivery, $\mathrm{Fe}_{3} \mathrm{O}_{4}$ nanoparticles are used for their ability to be driven by external magnetic force and thus achieving direct drug targeting. Moreover magnetic nanoparticle once been exposed to an alternate magnetic field could be used for controlled release of drug components embedded inside a polymer. Therefore, incorporation of magnetic particles in electrospun nanofibers could offer enhanced drug delivery efficacy (19-29).

It is difficult to disperse magnetic $\mathrm{Fe}_{3} \mathrm{O}_{4}$ nanoparticles homogeneously in a polymer matrix because of a difference in density and polarity between nanoparticles and polymer. On one hand, surface modification of magnetic particles before integration in chitosan (CS) nanofibers prevents aggregation of particles allowing a uniform distribution in fibers. On the other hand, the modification could increase the chemical stability of the $\mathrm{Fe}_{3} \mathrm{O}_{4}$ NPs and could improve the biocompatibility of the NPs. In addition, using cross-linker allows enhanced loading properties for functional molecules.

In this work, $\mathrm{Fe}_{3} \mathrm{O}_{4}$ NPs were modified with $\mathrm{CS}$ nanoparticles by using glutaraldehyde (GA) and sodium tri polyphosphate (TPP) as cross-linkers (Fig. 1). Using cross-linker allows enhanced loading properties for functional molecules and also proteins in addition to providing a uniform distribution of magnetic nanoparticles in the fibers. The two terminal aldehyde 


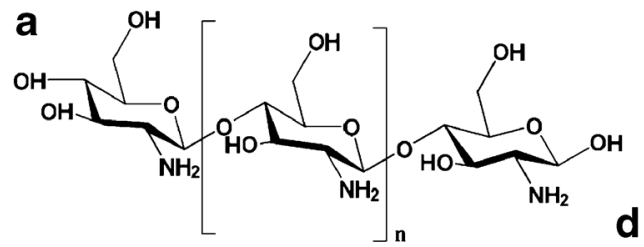

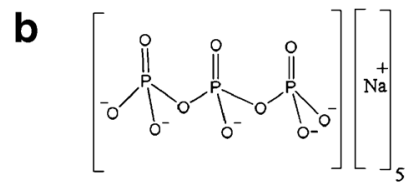

C

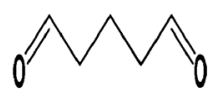

d
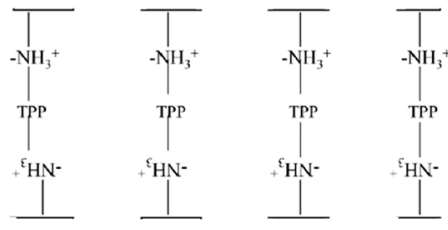

e

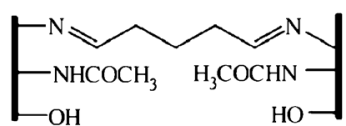

Fig. 1. Molecular structure of a chitosan (CS), poly-(D)-glucosamine, b glutaraldehyde (GA), c sodium triphosphate (TPP), and $\mathbf{d}$, e cross-linking reaction of CS with TPP and GA

groups of glutaraldehyde react with amino groups, resulting in cross-linking of those chains through glutaraldehyde. Linkage of both terminal aldehyde groups with separate chitosan molecules results in cross-linking, while the linkage of only one aldehyde group results in the activation of surface for protein loading. On the other hand, TPP is a cross-linker which links the amide groups resulting in formation of CS nanoparticles and also allowing a linkage with other functional molecules. First surface of $\mathrm{Fe}_{3} \mathrm{O}_{4}$ nanoparticles were modified with TPP and GA crosslinkers and then CS were further added to form CS nanoparticles with cross-linkers absorbed on the surface of $\mathrm{Fe}_{3} \mathrm{O}_{4}$. BSA was used as a model of protein drugs which was encapsulated and released from cross-linked nanofibers. Effect of cross-linker in magnetic NP distribution, nanofiber network morphology, and subsequently protein release was studied. This work seeks to explore efficient loading of drugs and the possibility to achieve controlled release from scaffold by means of magnetic properties and therefore offers an important biomedical material.

\section{MATERIALS AND METHODS}

\section{Materials}

Iron(III) chloride hexahydrate $\left(\mathrm{FeCl}_{3} \cdot 6 \mathrm{H}_{2} \mathrm{O}\right)$, $\left(\mathrm{FeCl}_{2} \cdot 4 \mathrm{H}_{2} \mathrm{O}\right)$ was purchased from Merck Co. Medium molecular weight chitosan (CTS, 75 and $85 \%$ deacetylated), bovine serum albumin (BSA), and acetic acid (TFA,_98\%) were purchased from Sigma-Aldrich Co. The polyvinyl alcohol (PVA Z-410, Japan Synthetic Chemical Co.) had a degree of deacetylation of $97.0 \pm 0.5 \%$ and a MW of $1.2 \times 105 \mathrm{gmol}^{-1}$.

\section{$\mathrm{Fe}_{3} \mathrm{O}_{4}$ Nanoparticle Synthesis}

$\mathrm{Fe}_{3} \mathrm{O}_{4}$ nanoparticles were prepared by modified coprecipitation route. $\mathrm{FeCl}_{2} \cdot 4 \mathrm{H}_{2} \mathrm{O}, \mathrm{FeCl}_{3} \cdot 6 \mathrm{H}_{2} \mathrm{O}$ (Merck) was used as precursors. A solution of $\mathrm{FeCl}_{2} \cdot 4 \mathrm{H}_{2} \mathrm{O}, \mathrm{FeCl}_{3} \cdot 6 \mathrm{H}_{2} \mathrm{O}$ with molar ratio of 1.5:1 was prepared under ultrasonic agitation via ultrasonication $(10 \mathrm{~min}, 100 \mathrm{~W})$ to ensure homogenous mixing, subsequently ultracentrifuged, and black precipitate was produced immediately by adding sodium hydroxide. Dried nitrogen gas was inflated during synthesis in a closed system to prevent the oxidization of ferrous ions.

\section{$\mathrm{Fe}_{3} \mathrm{O}_{4} / \mathrm{CS} / \mathrm{TPP}$ Nanocomposites}

A suspension of $\mathrm{Fe}_{3} \mathrm{O}_{4}$ nanoparticles were prepared by adding $25 \mathrm{mg}$ of $\mathrm{Fe}_{3} \mathrm{O}_{4}$ in 50-ml deionized water. $100 \mu \mathrm{L} \mathrm{GA}$ was dropped to the above solution with continual stirring at $500 \mathrm{rpm}$ for $1 \mathrm{~h}$ to form an adsorption layer of GA around $\mathrm{Fe}_{3} \mathrm{O}_{4}$ nanoparticles. In order to remove unbounded GA, procedures of washing and dispersion were adopted. CS was dissolved in acetic acid and added to the reaction system in order to obtain a final CS solution of $2 \% w / v(0.4 \mathrm{~g}$ of CS in $20 \mathrm{ml}$ acetic acid) followed by the coating process for $2 \mathrm{~h}$. To cross-link the exterior of loaded CS layer, GA was dropped into the flask, the cross-linking reaction was completed after $2 \mathrm{~h}$ later, and the final products were gathered with a permanence magnet. $\mathrm{Fe}_{3} \mathrm{O}_{4}$-CS nanoparticles were prepared by cross-linking with sodium tripolyphosphate (TPP). Specifically, $20 \mathrm{mg}$ TPP were added to a solution of $500 \mathrm{ppm}$ $\mathrm{Fe}_{3} \mathrm{O}_{4}$ and stirred for $1 \mathrm{~h}$. The solution was washed and redispersed in deionized water. $0.4 \mathrm{~g}$ CS were dissolved in $20 \mathrm{ml}$ of acetic acid and added to reaction system in order to cross-link with TPP absorbed on $\mathrm{Fe}_{3} \mathrm{O}_{4}$ nanoparticles. After stirring for $30 \mathrm{~min}, \mathrm{Fe}_{3} \mathrm{O}_{4} / \mathrm{TPP} / \mathrm{CS}$ nanoparticles were collected and used to produce nanofibers by means of electrospinning process.

\section{Fabrication of $\mathrm{Fe}_{3} \mathrm{O}_{4} / \mathrm{CS} / \mathrm{PVA}$ Nanofibrous Membranes by Electrospinning Process}

Electrospinning of CS was performed with PVA solution. To this regard, $10 \%$ PVA were prepared and stirred for $4 \mathrm{~h}$ in $80^{\circ} \mathrm{C}$. CS solution $(2 \% \mathrm{w} / \mathrm{v})$ was prepared and mixed with PVA in different ratios of 30:70 and 20:80. For fabrication of $\mathrm{Fe}_{3} \mathrm{O}_{4} / \mathrm{CS} / \mathrm{PVA}$, $500 \mathrm{ppm}$ of prepared $\mathrm{Fe}_{3} \mathrm{O}_{4}$ was directly mixed with CS/PVA. Also, $\mathrm{Fe}_{3} \mathrm{O}_{4} / \mathrm{GA} / \mathrm{CS}$ and $\mathrm{Fe}_{3} \mathrm{O}_{4} / \mathrm{TPP} / \mathrm{CS}$ solutions were mixed with PVA at ratio of 30:70 and electrospun. Namely CS/PVA, $\mathrm{Fe}_{3} \mathrm{O}_{4} / \mathrm{CS}$-PVA, $\mathrm{Fe}_{3} \mathrm{O}_{4} / \mathrm{GA} /$ 
CS/PVA, and $\mathrm{Fe}_{3} \mathrm{O}_{4} / \mathrm{TPP} / \mathrm{CS} / \mathrm{PVA}$ were fabricated by means of electrospinning. The polymer solution was delivered at a constant flow rate of $8 \mathrm{ml} / \mathrm{h}$ connected to a high-voltage power supply. Upon applying a high voltage $(18 \mathrm{kV})$, a fluid jet was ejected from the capillary. The distance of collector from syringe was set to $15 \mathrm{~cm}$ as the jet accelerated towards a grounded collector, the solvent evaporated, and a charged polymer fiber was deposited on the collector in the form of a non-woven fabric.

\section{Nanofiber Characterization}

The magnetite nanoparticle sample was characterized by Fourier transform infrared spectroscopy (FTIR) and field emission scanning electron microscopy (FESEM) analysis. The FESEM micrographs were taken using a FESEM, Hitachi and model S-4160. FT-IR absorption spectra of selected samples were obtained using $\mathrm{KBr}$ disks on a FTIR 6300. Electrospinning was performed on Electroris ${ }^{\circledR}$, ElectrorisNL, and Fanavaran Nano-meghyas Co. Iran.

\section{Preparation of BSA-Loaded CS Nanofibers}

Bovine serum albumin (BSA) was loaded into CS nanofibers by interaction onto CS-TPP absorbed on $\mathrm{Fe}_{3} \mathrm{O}_{4}$ nanoparticles. Specifically, after absorption of TPP on $\mathrm{Fe}_{3} \mathrm{O}_{4}$ nanoparticles, chitosan nanoparticles were added to cross-link via TPP coacervation, and the particle-containing solution was then mixed with solutions containing BSA at predetermined concentrations $(3-10 \mathrm{mg})$. The mixed solutions were gently stirred for $60 \mathrm{~min}$ to allow protein adsorption on the nanoparticles. The solution was mixed with PVA and eletrospun to form nanofibers. The concentration of BSA loaded into nanofibers was evaluated by Bradford assay. To this aim, surface of $1 \times 1 \mathrm{~cm}$ of collected nanofibers were put into contact with $3 \mathrm{ml}$ of Comassie Brilliant Blue G-250. The absorbance value was detected UV spectrophotometer at $595 \mathrm{~nm}$.

\section{In Vitro Drug Release Experiments}

Ten milligrams of BSA was dispersed into $10 \mathrm{~g}$ of $\mathrm{Fe}_{3} \mathrm{O}_{4}$ NPs containing PVA/CS solution with the weight ratio of 70/ 30 , which was stirred for $24 \mathrm{~h}$. The mixed solution was electrospun into nanofibers. The obtained BSA loaded hybrid nanofibers were taken off from the aluminum foil. The dried nanofibers $(8 \mathrm{mg}$ ) were immersed into $2 \mathrm{~mL}$ pH 7.4 phosphate buffer solution (PBS) at $37^{\circ} \mathrm{C}$. At periodic interval, the release media was collected and another 2-mL fresh PBS solution was added. The amount of BSA was determined by measuring the adsorption at $595 \mathrm{~nm}$ and using calibration curves.

\section{RESULTS AND DISCUSSION}

Chitosan, poly-(D)-glucosamine is a favorable dispersant for many types of small particulates, including $\mathrm{Fe}_{3} \mathrm{O}_{4}$ magnetic nanoparticles and can be used in the preparation of fibers by electrospinning (30-33). For electrospining, chitosan as a weak base was dissolved in acetic acid (weak acid) and the solution showed a good stability. Acetic acid evaporated completely after electrospinning which has no disadvantage in biomedical application of nanofibers. At the first stage, pure chitosan without magnetic nanoparticles was electrospanned. Electrospinning of pure chitosan is limited since chitosan solutions are highly viscous which complicates its electrospinning (34). Furthermore, the formation of strong hydrogen bonds in a 3-D network prevents the movement of polymeric chains exposed to the electrical field. In order to produce nanofibers, PVA was added to chitosan solutions in ratios of 80:20 and 70:30. The microstructure measurement which is advanced image analyzer software was applied to the fabricated nanoparticles and nanofibers for size measurement. The size measurement was carried out for 10 different points in the synthesized sample and the average of those 10 measured sizes was calculated. Figure 2 shows the SEM image of nanofiber with PVA/CS ratio of 70:30 and 80:20 which shows average fiber thickness of $350 \mathrm{~nm}$. The fiber thickness was decreased with the PVA/CS ratio of 80:20 with more uniform fibers. Electrospinning of chitosan nanofibers was achievable in the presence of PVA. Moreover, increasing PVA resulted in decreasing nanofibers thickness with homogenous nanofibers due to the reduced repulsive interaction between polycation groups.

Magnetic nanoparticles were added to the PVA/CS solution using three different methods. In the first method, magnetic nanoparticles were added directly to the PVA/CS solution. In the second and third methods, magnetic nanoparticles and chitosan were cross-linked using glutaraldehyde (GA) (Fig. 1e) or tripolyphosphate (TPP) (Fig. 1d) and added to PVA solution for electrospinning, respectively. Magnetic nanoparticles showed an average size of $45 \mathrm{~nm}$ (Fig. 3a). When glutaraldehyde or tripolyphosphate was used as cross-
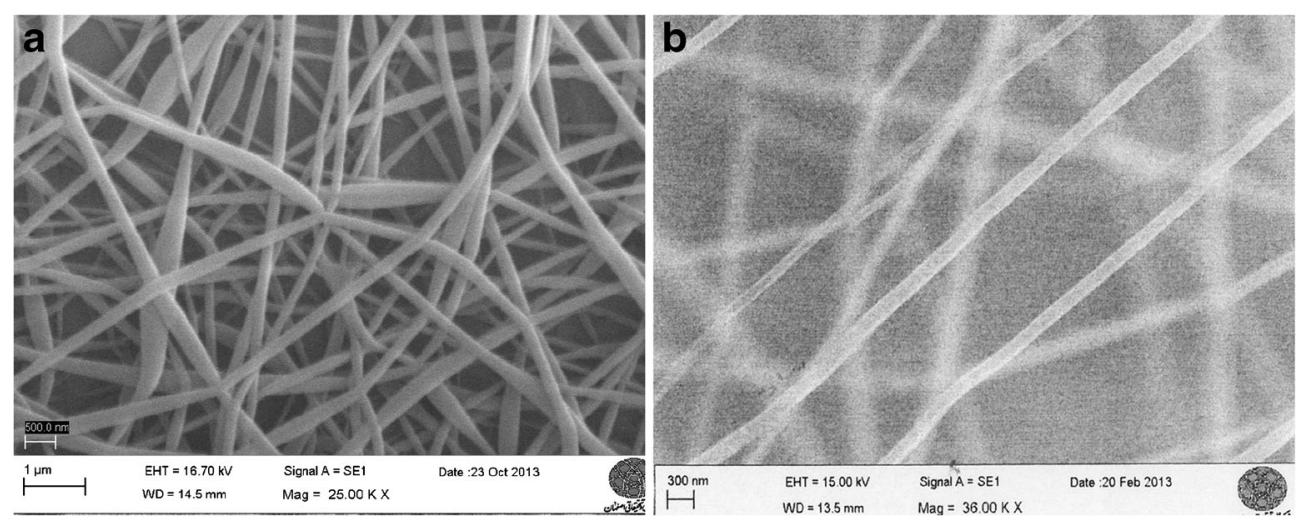

Fig. 2. SEM image of electrospun CS-PVA nanofibers with a 70:30 and b 80:20 ratio of PVA to CS 

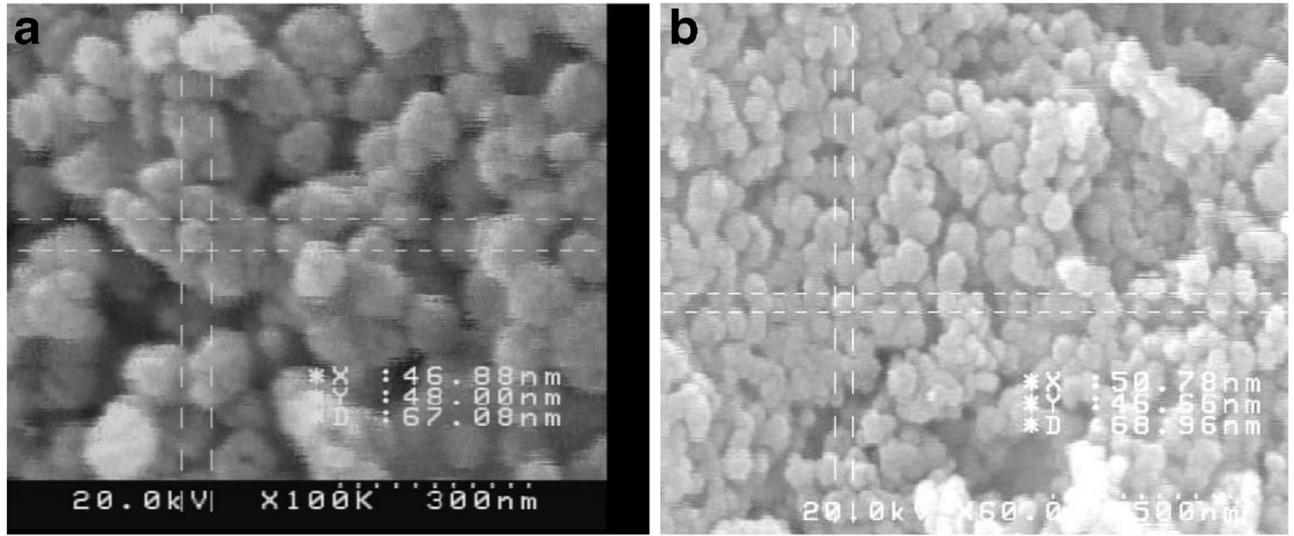

Fig. 3. FESEM image of $\mathbf{a} \mathrm{Fe}_{3} \mathrm{O}_{4}$ and $\mathbf{b} \mathrm{Fe}_{3} \mathrm{O}_{4} / \mathrm{CS}$ nanoparticles

linker to form CS layer, the average size of nanoparticle was $51 \mathrm{~nm}$ showing the absorbance of a layer on magnetic/CS nanoparticles (Fig. 3b).

The irreversible Schiff's base linking of aldehyde with amino group provides stability (35). The cross-linking reaction of chitosan in acetic acid proceeds with a high rate $(36,37)$. In the case of GA, a "double-crosslinking" method was utilized to synthesize $\mathrm{Fe}_{3} \mathrm{O}_{4} / \mathrm{GA}$. Firstly, GA as cross-linking agent was used to be absorbed onto the surface of $\mathrm{Fe}_{3} \mathrm{O}_{4}$ before CS loading. After CS loading, GA was used again to cross-link the adsorbed CS, so that the solvent resistance of as-obtained nanosphere would be enhanced.

The solution of $\mathrm{Fe}_{3} \mathrm{O}_{4} / \mathrm{CS} / \mathrm{GA}$ showed good stability which magnetic particles were uniformly distributed without aggregation. In this case, a uniform dispersion of magnetic nanoparticles in the nanofibers could be achieved.

On the other hand, TPP reacts with its negative site to the amide group of chitosan forming CS nanoparticles. A variety of functional molecules could be applied and absorbed onto the surface of $\mathrm{CS} / \mathrm{Fe} 3 \mathrm{O} 4$ particles with this method.

The chemical structure of all cross-linked nanofibers, CS/ $\mathrm{Fe}_{3} \mathrm{O}_{4} / \mathrm{PVA}$, CS/GA/ $\mathrm{Fe}_{3} \mathrm{O}_{4} / \mathrm{PVA}$, and $\mathrm{CS} / \mathrm{TPP} / \mathrm{Fe}_{3} \mathrm{O}_{4} / \mathrm{PVA}$ prepared by electrospinning from PVA aqueous solution was investigated using SEM and FTIR.

In sample of $\mathrm{CS} / \mathrm{Fe}_{3} \mathrm{O}_{4} / \mathrm{PVA}$ which the magnetic nanoparticles were added directly to the solution, distribution of $\mathrm{Fe}_{3} \mathrm{O}_{4}$ were not uniform and aggregations were formed (Fig. 4). The size of nanofibers was found to be $300 \mathrm{~nm}$, and at some points, irregular shape nanofibers were formed.

SEM image of sample CS/GA/Fe3O4/PVA showed a complex network of tissue nanofibers. The length of each fiber was decreased, and terminal sides of nanofibers were attached to each other resulting in a complex network (Fig. 5a). This is due to the presence of GA as a strong cross-linker which has probably cross-linked CS/CS nanofibers producing a network scaffold. It is assumed that the release of functional molecules from these fibers takes place slower due to the network.

The magnetic nanoparticles were attached strongly to the nanofibers which had deformed the fibers in some point. Fibers with the average size of $150 \mathrm{~nm}$ and in some parts spindle shape were detected in this sample.

Electrospinning of $\mathrm{CS} / \mathrm{TPP} / \mathrm{Fe}_{3} \mathrm{O}_{4} / \mathrm{PVA}$ resulted in complete smooth and homogenous nanofibers where the magnetic nanoparticles were distributed uniformly without aggregation in the scaffold (Fig. 5b). The average size of nanofibers was $150 \mathrm{~nm}$, and nanoparticles with smaller size compared to the other samples were detected. Applying cross-linkers enhanced the dispersion of magnetic NPs in terms of size and uniform dispersion.

The best electrospun nanofibers were obtained in sample of CS/TPP/Fe3O4/PVA in terms of a uniform combination of nanofibers and nanoparticles. It was concluded that TPP acts as PVA in enhancing electrospinning ability of chitosan. Due to the properties of TPP in forming a linkage with functional molecules, these nanofibers are a suitable candidate for loading drugs.

The presence of PVA, CS, GA, TPP and $\mathrm{Fe}_{3} \mathrm{O}_{4}$ in the composite fibers was confirmed by FTIR (Fig. 6).

For pure PVA, absorption bands that are around 2940, 1660, 1430, and $1090 \mathrm{~cm}^{-1}$ correspond to the $\mathrm{C}-\mathrm{H}, \mathrm{C}=\mathrm{O}, \mathrm{CH}_{2}$ and C-N groups, respectively (Fig. 6a) $(38,39)$. In the case of $\mathrm{Fe}_{3} \mathrm{O}_{4}$, the absorption at $585 \mathrm{~cm}^{-1}$ is assigned to $\mathrm{Fe}-\mathrm{O}$ vibrations $(40,41)$. The FTIR spectra of each set of fibers show a combination of the characteristic bands of PVA, CS, and $\mathrm{Fe}_{3} \mathrm{O}_{4}$, confirming that PVA, CS, and $\mathrm{Fe}_{3} \mathrm{O}_{4}$ are all present in the composite materials. The cross-linking and activation with glutaraldehyde were confirmed by FTIR spectra.

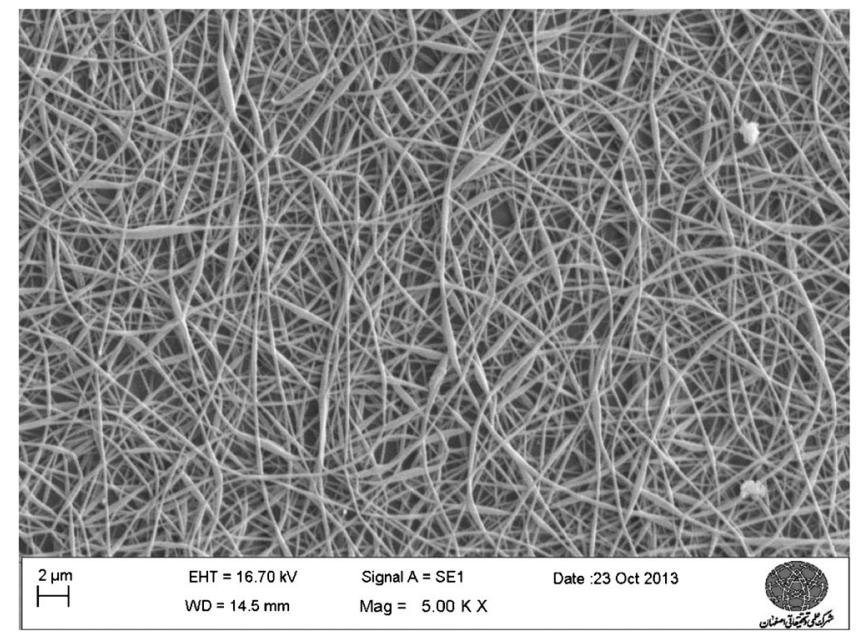

Fig. 4. SEM image of electrospun $\mathrm{Fe}_{3} \mathrm{O}_{4} / \mathrm{CS} / \mathrm{PVA}$ nanofibers 
a
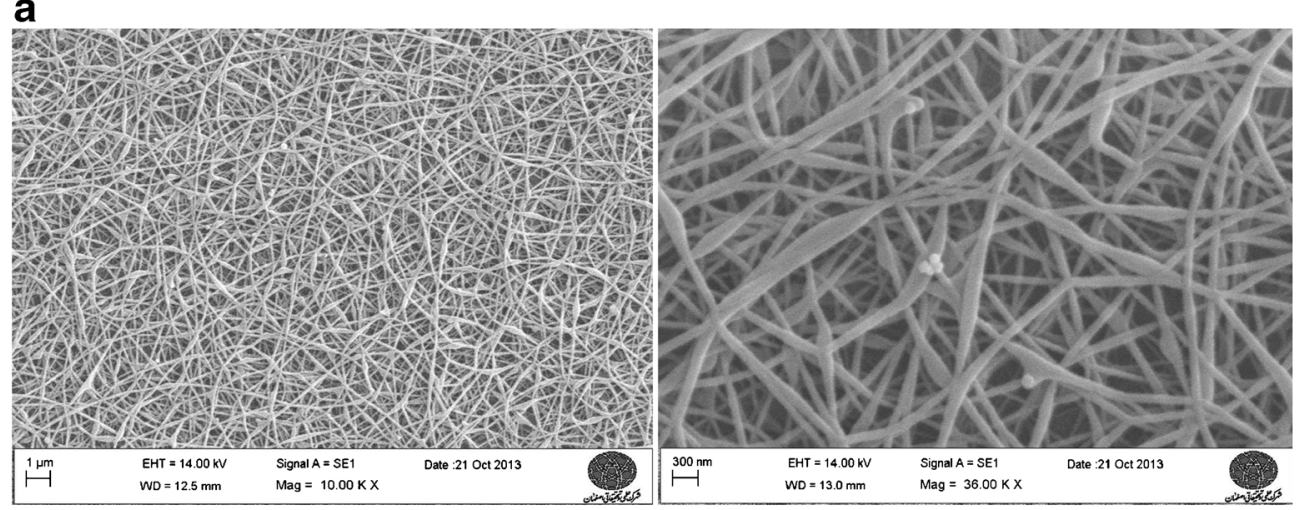

b

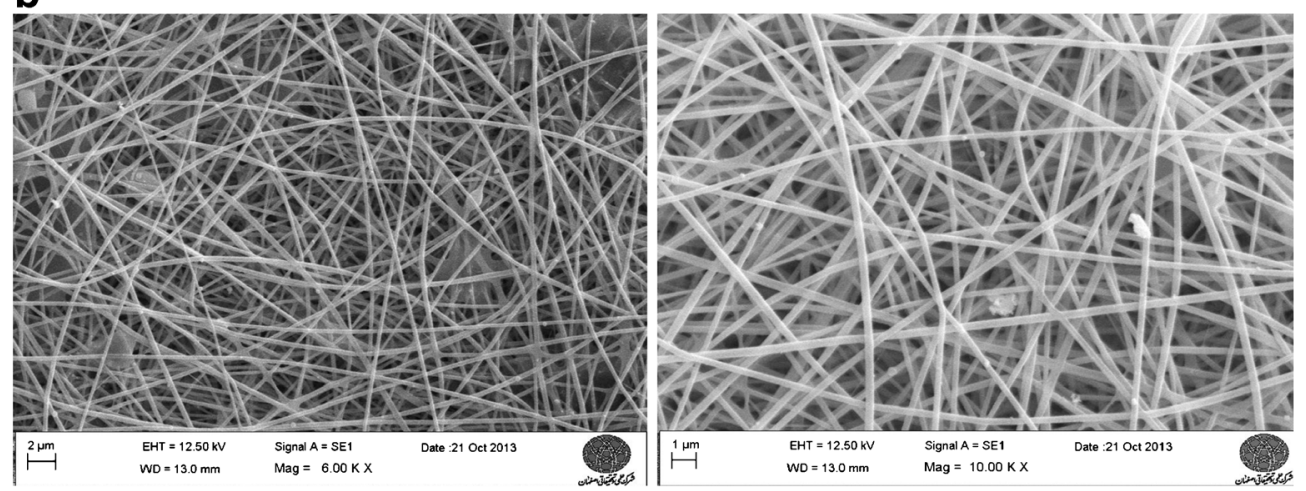

Fig. 5. SEM image of electrospun $\mathbf{a} \mathrm{Fe}_{3} \mathrm{O}_{4} / \mathrm{CS} / \mathrm{GA}$ : PVA nanofibers and $\mathbf{b} \mathrm{Fe}_{3} \mathrm{O}_{4} / \mathrm{CS} / \mathrm{TPP}$ : PVA nanofibers

The peak at $1412 \mathrm{~cm}^{-1}$ represents the $\mathrm{C}-\mathrm{N}$ bond results with a cross-linking reaction (Fig. 6b). The aldehyde groups of glutaraldehyde molecules react with the amino group of chitosan through schiff base linkage. Other peaks at 1646 and $1054 \mathrm{~cm}^{-1}$ may attributed to $\mathrm{C}=\mathrm{N}$ and polysaccharide structure. For the electrospun sample of $\mathrm{CS}-\mathrm{Fe}_{3} \mathrm{O}_{4}$-PVA cross-linked by tripolyphosphate ( $\left.\mathrm{CS} / \mathrm{TPP} / \mathrm{Fe}_{3} \mathrm{O}_{4} / \mathrm{PVA}\right)$, absorption bands at around 1230 and $1140 \mathrm{~cm}^{-1}$ correspond to the $\mathrm{P}=\mathrm{O}$, group (Fig. 6c). The cross-linking with

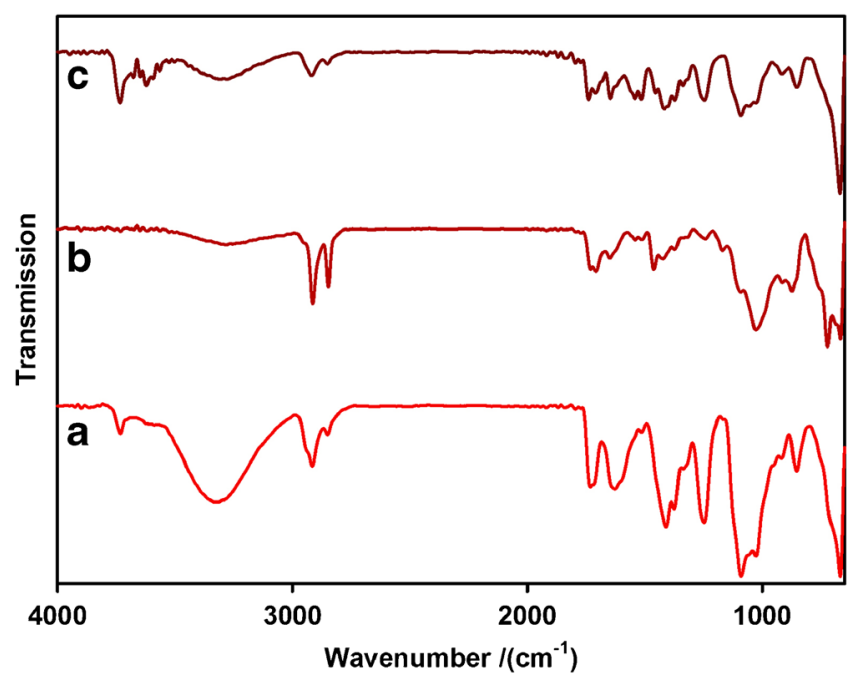

Fig. 6. FTIR spectra of $\mathbf{a} \mathrm{Fe}_{3} \mathrm{O}_{4} / \mathrm{CS} / \mathrm{PVA}, \mathbf{b} \mathrm{Fe}_{3} \mathrm{O}_{4} / \mathrm{CS} / \mathrm{GA} / \mathrm{PVA}$ and $\mathbf{c}$ $\mathrm{Fe}_{3} \mathrm{O}_{4} / \mathrm{CS} / \mathrm{TPP} / \mathrm{PVA}$, (chitosan/PVA, 30:70) tripolyphosphate was confirmed by FTIR spectra. The peak at $1644 \mathrm{~cm}^{-1}$ represents the cross-linking of tripolyphosphate molecule with the amino group of chitosan through $\mathrm{C}=\mathrm{N}(42-46)$. Cross-linking of nanofiber with glutaraldehyde is associated with the absorption peak near $1090 \mathrm{~cm}^{-1}$. This indicates the formation of acetal ring with increasing PVA-glutaraldehyde cross-linking reaction time. The IR spectra also show a broad $\mathrm{O}-\mathrm{H}$ stretching and an alkyl $\mathrm{C}-\mathrm{H}$ stretching vibration absorption around 3300 and $2900 \mathrm{~cm}^{-1}$ is related to cross-link of PVA nanofiber with glutaraldehyde. Moreover, the PVA O-H stretching band to higher wave number can be attributed to the hydrogen bonding among $\mathrm{O}-\mathrm{H}$ groups of PVA cross-link with glutaraldehyde.

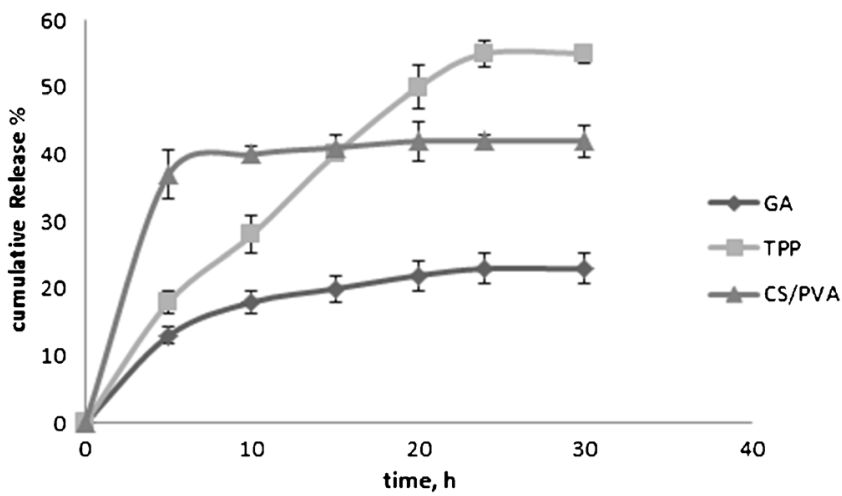

Fig. 7. In vitro release profile of BSA loaded $\mathrm{Fe}_{3} \mathrm{O}_{4}$ containing PVA/ CS nanofibers (weight ratio of PVA/CS: 70/30) with different crosslinkers at $37^{\circ} \mathrm{C}$ and $\mathrm{pH} 7.4$ 
To investigate the in vitro drug release behavior of the cross-linked PVA/CS hybrid nanofibers, BSA as a model of protein drugs was loaded into the fibers with an encapsulation efficiency of $100 \%$. The non-crosslinked nanofibers released BSA molecules within $3 \mathrm{~h}$ (Fig. 7). Consequently, the purpose of sustaining and controlled drug release could not be achieved by these nanofibers. Contrast to this cross-linked, TPP nanofibers released $60 \%$ of BSA in $30 \mathrm{~h}$. GA crosslinked nanofibers decreased the rate of release to a slower and low release to $30 \%$ after $30 \mathrm{~h}$. This is attributed to the complex network of cross-linked GA nanofibers which has largely slowed the release rate.

There are few methods for measuring the porosity such as conventional methods using apparent density and bulk density, image analysis by FESEM and transmission electron microscopy (TEM), mercury porometer, and BrunauerEmmett-Teller (BET). However till date, an accurate estimation of porosity in these grades of materials (nanofiber mat) has been a difficult task. The misleading results could be obtained via mercury porosimetry due to the mechanical deformation of the nanofibers and BET measurements lead to only specific surface area value. Also simple experiment based on liquid absorption can be inaccurate due to swelling of nanofibers in the liquid.

The FESEM result indicated GA cross-linked nanofibers have smaller pore compared to TPP nanofibers which is due to cross-linked CS-CS fibers. This will lead to a lower porosity. Due to the fact that release through diffusion is lower in these fibers, proteins were released in low concentrations in GA cross-linked nanofibers.

The release burst in the initial stage of experiments could be explained as follows: the swelling of the soluble polymers in physiological condition $(\mathrm{pH}=7.4)$ was inevitable although part of the $\backslash \mathrm{NH} 2$ on CS chains and BSA was cross-linked together. Accordingly, BSA molecules near the surface of the hybrid fibers were diffused into the medium quickly. After that, the drug was released gradually deep into the fibers (47).

\section{CONCLUSION}

The magnetic nanoparticles $\left(\mathrm{Fe}_{3} \mathrm{O}_{4}\right)$ were effectively included in cross-linked electrospun chitosan nanofibers using different cross-linkers. These nanocomposites were used for BSA loading and release applications. The composite fibers which contained $\mathrm{Fe}_{3} \mathrm{O}_{4}$ nanoparticles were dispersed relatively uniform. Sodium tripolyphosphate (TPP) and glutaraldehyde (GA) as cross-linkers had effects on the size of the obtained composites. The characterization results suggest that $\mathrm{Fe}_{3} \mathrm{O}_{4}$ nanoparticles with average size of $45 \mathrm{~nm}$ were successfully bound on the surface of chitosan. Bovine serum albumin (BSA) was used as a model protein which was encapsulated to form CS/BSA/TPP/ $/ \mathrm{Fe}_{3} \mathrm{O}_{4}$ and $\mathrm{CS} / \mathrm{BSA} / \mathrm{GA} / \mathrm{Fe}_{3} \mathrm{O}_{4}$ nanoparticles. These nanocomposites were electrospun with poly vinyl alcohol (PVA) to form cross-linked nanofibers. The composite structure was confirmed by characterization techniques, field emission scanning electron microscopy (FESEM), and Fourier transform infrared spectroscopy (FTIR). FTIR data show that these two polymers have intermolecular interaction. The best sample was considered to be TPP cross-linked nanofibers in terms of uniform and homogenous CS/PVA nanofibers with fine distribution of $\mathrm{Fe}_{3} \mathrm{O}_{4}$ nanoparticles. A controlled slow release rate with higher amount of BSA release to $60 \%$ after $30 \mathrm{~h}$ was obtained. These electrospun magnetic chitosan nanocomposite fibrous networks could be used for efficient controlled release of proteins due to their magnetic properties. Hence, these magnetic electrospun chitosan nanofiber composites have great potential for biomedical applications.

\section{ACKNOWLEDGMENTS}

This work was financially supported by Isfahan University of Technology.

\section{REFERENCES}

1. Aikifa R, Jiaqi W, Shan Y, Yang S, Ding B. Hierarchical porous carbon nanofibers via electrospinning. Carbon Lett. 2014;15(1):1-14.

2. Martins A, Reis RL, Neves NM. Electrospinning: processing technique for tissue engineering scaffolding. Int Mater Rev. 2008;53(5):257-74.

3. Shalumon KT, Anulekha KH, Girish CM, Prasanth R, Nair SV, Jayakumar R. Single step electrospinning of chitosan/ poly(caprolactone) nanofibers using formic acid/acetone solvent mixture. Carbohydr Polym. 2010;80(2):413-9.

4. Bhattarai N, Edmondson D, Veiseh O, Matsen FA, Zhang M. Electrospun chitosan-based nanofibers and their cellular compatibility. Biomaterials. 2005;26(31):6176-84.

5. Khil MS, Kim HY, Kim MS, Park SY, Lee D-R. Nanofibrous mats of poly(trimethylene terephthalate) via electrospinning. Polymer. 2004;45(1):295-301.

6. Li X, Cui R, Sun L, Aifantis KE, Fan Y, Feng Q, et al. 3D-printed biopolymers for tissue engineering application. Int J Polym Sci. 2014;2014:13.

7. Wang $X$, Ding B, Li B. Biomimetic electrospun nanofibrous structures for tissue engineering. Mater Today. 2013;16(6):229-41.

8. Du J, Yarema KJ. Carbohydrate engineered cells for regenerative medicine. Adv Drug Deliv Rev. 2010;62(7-8):671-82.

9. Holzwarth JM, Ma PX. Biomimetic nanofibrous scaffolds for bone tissue engineering. Biomaterials. 2011;32(36):9622-9.

10. Griffith LG, Naughton G. Tissue engineering-current challenges and expanding opportunities. Science. 2002;295(5557):1009-14.

11. Vasita R, Katti DS. Nanofibers and their applications in tissue engineering. Int J Nanomedicine. 2006;1(1):15-30.

12. Homaeigohar S, Elbahri M. Nanocomposite electrospun nanofiber membranes for environmental remediation. Materials. 2014;7(2):1017-45.

13. Sundarrajan S, Ramakrishna S. Fabrication of nanocomposite membranes from nanofibers and nanoparticles for protection against chemical warfare stimulants. J Mater Sci. 2007;42(20):8400-7.

14. Gugliuzza A, Drioli E. A review on membrane engineering for innovation in wearable fabrics and protective textiles. J Membr Sci. 2013;446:350-75.

15. Ramaseshan R, Ramakrishna S. Zinc titanate nanofibers for the detoxification of chemical warfare simulants. J Am Ceram Soc. 2007;90(6):1836-42.

16. Roso M, Sundarrajan S, Pliszka D, Ramakrishna S, Modesti M. Multifunctional membranes based on spinning technologies: the synergy of nanofibers and nanoparticles. Nanotechnology. 2008;19(28):285707.

17. Sundarrajan S, Pliszkal D, Jaworek A, Krupa A, Lackowski M, Ramakrishna S. A novel process for the fabrication of nanocomposites membranes. J Nanosci Nanotechnol. 2009;9(7):4442-7.

18. Rogers CM, Morris GEGT, Bail R, Toumpaniari S, Harrington $\mathrm{H}$, Dixon JE, et al. A novel technique for the production of electrospun scaffolds with tailored three-dimensional micro-patterns employing additive manufacturing. Biofabrication. 2014;6(3):035003.

19. Yan W, Xuehui Z, Yu S, Bing H, Xiaoyang H, Xinzhi W, et al. Magnetic biodegradable Fe 3 O 4 /CS/PVA nanofibrous membranes for bone regeneration. Biomed Mater. 2011;6(5):055008. 
20. Habibi N. Immobilization of bacterial S-layer proteins from Caulobacter crescentus on iron oxide-based nanocomposite: synthesis and spectroscopic characterization of zincite-coated $\mathrm{Fe}_{3} \mathrm{O}_{4}$ nanoparticles. Spectrochim Acta A Mol Biomol Spectrosc. 2014;125:359-62.

21. Habibi N. Preparation of biocompatible magnetite-carboxymethyl cellulose nanocomposite: characterization of nanocomposite by FTIR, XRD, FESEM and TEM. Spectrochim Acta A Mol Biomol Spectrosc. 2014;15:55-8.

22. Habibi N, Karimi B. Fabrication and characterization of zinc oxide nanoparticle coated magnetic iron oxide: Effect of Slayers adsorption on surface of oxide. J Ind Eng Chem. 2014;20(5):3033-6.

23. Habibi N, Pastorino L, Sandoval OH, Ruggiero C. Polyelectrolyte based molecular carriers: the role of selfassembled proteins in permeability properties. J Biomater Appl. 2013;28(2):262-9.

24. Habibi N, Pastorino L, Soumetz FC, Sbrana F, Raiteri R, Ruggiero C. Nanoengineered polymeric S-layers based capsules with targeting activity. Colloids Surf B: Biointerfaces. 2011;88(1):366-72.

25. Pastorino L, Habibi N, Soumetz FC, Giulianelli M, Ruggiero C. Polyelectrolyte multilayers for cell and tissue engineering. Eur Cells Mater. 2011;22(3)66.

26. Habibi N, Pastorino L, Sandoval OH, Ruggiero C. Polyelectrolyte based molecular carriers: The role of self-assembled proteins in permeability properties. J Biomater Appl. 2013;262-9.

27. Habibi N, Pastorino L, Ruggiero C. Biomimmetic structures: Incorporation of active bio-molecules in polyelectrolyte shells. Nanotechnology (IEEE-NANO), 2012 12th IEEE Conference on; 2012. doi:10.1109/NANO.2012.6322159.

28. Habibi N, Pastorino L, Soumetz FC, Ruggiero C. Permeability of Slayer coated polyelectrolyte capsules. Nanotechnology (IEEE-NANO), 2011 11th IEEE Conference on; 2011. doi:10.1109/NANO.2011.6144339.

29. Habibi N, Soumetz FC, Pastorino L, Herrera O, Ruggiero C. Layer by layer self assembly of Polyelectrolytes and S-layers. Nanotechnology (IEEE-NANO), 2010 10th IEEE Conference on; 2010. doi:10.1109/NANO.2010.5697853.

30. Lu X, Wang C, Wei Y. One-dimensional composite nanomaterials: synthesis by electrospinning and their applications. Small. 2009;5(21):2349-70.

31. Ahmad M, Pan C, Luo Z, Zhu J. A single ZnO nanofiber-based highly sensitive amperometric glucose biosensor. J Phys Chem C. 2010;114(20):9308-13.

32. Wang H, Li Y, Sun L, Li Y, Wang W, Wang S, et al. Electrospun novel bifunctional magnetic-photoluminescent nanofibers based on $\mathrm{Fe} 2 \mathrm{O} 3$ nanoparticles and europium complex. J Colloid Interface Sci. 2010;350(2):396-401.

33. Miyauchi M, Simmons TJ, Miao J, Gagner JE, Shriver ZH, Aich $\mathrm{U}$, et al. Electrospun polyvinylpyrrolidone fibers with high concentrations of ferromagnetic and superparamagnetic nanoparticles. ACS Appl Mater Interfaces. 2011;3(6):1958-64.

34. Homayoni H, Ravandi SAH, Valizadeh M. Electrospinning of chitosan nanofibers: processing optimization. Carbohydr Polym. 2009;77(3):656-61.

35. Sorlier $\mathrm{P}$, Denuzière $\mathrm{A}$, Viton $\mathrm{C}$, Domard A. Relation between the degree of acetylation and the electrostatic properties of chitin and chitosan. Biomacromolecules. 2001;2(3):765-72.

36. Kildeeva NR, Perminov PA, Vladimirov LV, Novikov VV, Mikhailov SN. About mechanism of chitosan cross-linking with glutaraldehyde. Russ J Bioorg Chem. 2009;35(3):360-9.

37. Qiu D, An X. Controllable release from magnetoliposomes by magnetic stimulation and thermal stimulation. Colloids Surf B: Biointerfaces. 2013;104:326-9.

38. H-h S, Gong X, Williams GR, Quan J, Nie H-l, Zhu L-m, et al. Self-assembled magnetic liposomes from electrospun fibers. Mater Res Bull. 2014;53:280-9.

39. Bai J, Li Y, Zhang C, Liang X, Yang Q. Preparing AgBr nanoparticles in poly(vinyl pyrrolidone) (PVP) nanofibers. Colloids Surf A Physicochem Eng Asp. 2008;329(3):165-8.

40. Namdeo M, Bajpai SK. Chitosan-magnetite nanocomposites (CMNs) as magnetic carrier particles for removal of $\mathrm{Fe}$ (III) from aqueous solutions. Colloids Surf A Physicochem Eng Asp. 2008:320(1-3):161-8.

41. Tantipolphan R, Rades T, McQuillan AJ, Medlicott NJ. Adsorption of bovine serum albumin (BSA) onto lecithin studied by attenuated total reflectance Fourier transform infrared (ATRFTIR) spectroscopy. Int J Pharm. 2007;337(1-2):40-7.

42. Zhang K, Qian Y, Wang H, Fan L, Huang C, Yin A, et al. Genipincrosslinked silk fibroin/hydroxybutyl chitosan nanofibrous scaffolds for tissue-engineering application. J Biomed Mater Res A. 2010;95A(3):870-81.

43. Min B-M, Jeong L, Lee KY, Park WH. Regenerated silk fibroin nanofibers: water vapor-induced structural changes and their effects on the behavior of normal human cells. Macromol Biosci. 2006;6(4):285-92.

44. Kweon H, Ha HC, Um IC, Park YH. Physical properties of silk fibroin/chitosan blend films. J Appl Polym Sci. 2001;80(7):928-34.

45. Magoshi J, Mizuide M, Magoshi Y, Takahashi K, Kubo M, Nakamura S. Physical properties and structure of silk. VI. Conformational changes in silk fibroin induced by immersion in water at 2 to $130^{\circ} \mathrm{c}$. J Polym Sci Polym Phys Ed. 1979;17(3):515-20.

46. Chen X, Shao Z, Marinkovic NS, Miller LM, Zhou P, Chance MR. Conformation transition kinetics of regenerated Bombyx mori silk fibroin membrane monitored by time-resolved FTIR spectroscopy. Biophys Chem. 2001;89(1):25-34.

47. Yan E, Fan S, Li X, Wang C, Sun Z, Ni L, et al. Electrospun polyvinyl alcohol/chitosan composite nanofibers involving $\mathrm{Au}$ nanoparticles and their in vitro release properties. Mater Sci Eng C. 2013;33(1):461-5. 